\title{
EVENTOS DE FORMAÇÃO DE PROFESSORES: UMA PERSPECTIVA ETNOGRÁFICA SOBRE APRENDER A ENSINAR
}

\section{TEACHER EDUCATION EVENTS: AN ETHNOGRAPHIC PERSPECTIVE ON LEARNING TO TEACH}

\author{
Everton Vargas da Costa* \\ Margarete Schlatter*
}

\section{RESUMO}

O presente trabalho tem como objetivo apresentar evento de formação como um conceito produtivo para a pesquisa sobre formação de professores. O conceito foi desenvolvido com base em um estudo etnográfico (COSTA, 2013) que analisou as práticas de formação em reuniões de professores e em períodos entre as aulas em uma instituição de ensino de português como língua adicional. A formação de professores observada orientou-se por elementos da racionalidade prática e técnica (PÉREZ GÓMEZ, 1995) e por atividades de conhecimento na prática e reflexão na prática, conforme proposto por Schön (2000). As abordagens sobre formação de professores propostas por esses autores são discutidas à luz de fundamentos da pesquisa etnográfica (HAMMERSLEY; ATKINSON, 1995). Com base nos eventos de formação observados, o estudo mostra como as perspectivas teóricas de atividades de formação de professores podem ser descritas com base em dados etnográficos relativos às ações, aos tópicos e aos papéis de mais e menos experientes que os participantes constroem conjuntamente na interação. Os resultados da análise apontam que um evento de formação é um momento propício para aprender a ensinar, e, em sua constituição, são fundamentais as ações desempenhadas pelos participantes de solicitar ajuda e de narrar experiências prévias, tópicos relacionados a práticas de sala de aula, e a experiência dos participantes como agentes formadores e em formação.

Palavras-chave: Formação de professores; Português como língua adicional; Prática profissional.

\section{ABSTRACT}

This article aims to present teacher education event as a productive concept for research on teacher education. The concept was developed based on an ethnographic study (COSTA, 2013) that examined the in-service teacher practices in teacher meetings and in breaks between classes in a Portuguese as an additional language school. The teacher education practices observed showed elements of practical rationality and technical rationality (PEREZ GOMEZ, 1995)

\footnotetext{
* Harvard University, Cambridge, Massachusetts. EUA. edacosta@fas.harvard.edu

* Universidade Federal do Rio Grande do Sul ${ }_{i}$ Porto Alegre, RS. Brasil. margarete.schlatter@gmail. com
} 
and activities of knowledge-in-practice and reflection-in-action, as proposed by Schön (2000). The approaches to teacher education proposed by these authors are discussed in the light of an ethnographic research perspective (HAMMERSLEY; ATKINSON, 1995). Based on the teacher education events observed, the study shows how the theoretical perspectives on teacher education activities can be described based on ethnographic data concerning the actions, the topics and the more and less experienced roles the participants jointly construct in interaction. The results show that a teacher education event is a moment conducive to learning how to teach, and that it is constituted by the participants' actions of asking for help and narrating previous experiences, topics dealing with classroom practices, and the participants' experience both as teacher educators and in-service learners.

Keywords: Teacher education; Portuguese as an additional language; Professional practice.

\section{INTRODUÇÃO}

Nas duas últimas décadas, as discussões e ações sobre formação de professores têm avançado, pouco a pouco, para perspectivas mais sociais e situadas. O relatório "Formação Continuada de Professores: Uma análise das modalidades e das práticas em estados e municípios brasileiros" (2011)1 apresenta os resultados de uma pesquisa sobre a configuração atual das ações de formação continuada de professores em distintos estados e municípios brasileiros, as modalidades por meio das quais são implementadas e os processos de monitoramento e avaliação empregados. São identificadas duas abordagens de formação de professores: a primeira vê a formação continuada como desenvolvimento do sujeito professor, e a segunda vê a escola como locus de desenvolvimento de equipes pedagógicas e a formação de comunidades colaborativas de aprendizagem (FCC, 2011, p. 15).

O mesmo relatório traz o resultado de um estudo que buscou verificar quais são as ações mais comuns, nos estados e municípios brasileiros, em termos de formação continuada. Segundo a análise, em grande parte das Secretarias de Educação, o mais recorrente é uma formação instrumentalista e que não leva em consideração os saberes dos professores, sobretudo naqueles contextos em que se observou predominância de uma perspectiva individualizada de formação (FCC, 2011, p. 16-22). Por outro lado, em formações que privilegiam uma perspectiva colaborativa, as atividades em geral acontecem nas escolas, por meio de grupos de estudos, produção coletiva de materiais didáticos, envolvimento dos professores nos processos de planejamento e de implementação da sua própria avaliação, elaboração

1 Realizado pela Fundação Carlos Chagas, por encomenda da Fundação Victor Cívita. 
de projetos pedagógicos relativos aos conteúdos do currículo ou a problemas identificados em sala de aula, além da formação de redes virtuais de colaboração entre comunidades escolares (FCC, 2011, p. 23-29). Em suma, há ações de formação que investem na pessoa do professor, em sua vontade de aprender e em seu compromisso com os seus alunos, e as que veem, nos problemas, nos embates e nas virtudes do contexto de trabalho, oportunidades de aprendizagem docente.

Pensando o indivíduo, a profissão e o espaço escolar como três pilares de desenvolvimento do professor, entendemos que a observação das experiências produzidas e compartilhadas entre os participantes de um dado contexto situado historicamente é decisiva para compreender como acontece a formação de professores. Desde essa perspectiva, o presente trabalho tem o objetivo de apresentar evento de formação como conceito produtivo para a análise de ações de formação de professores. Como veremos a seguir, as práticas de formação de professores que caracterizam os eventos discutidos aqui são orientadas por elementos da racionalidade prática e técnica (PÉREZ GÓMEZ, 1995), envolvem conhecimento na prática e reflexão na prática (SCHÖN, 2001) e podem ser dimensionadas no âmbito pessoal, profissional e das equipes escolares (NÓVOA, 1995; 2007). Alinhados aos fundamentos da pesquisa etnográfica (HAMMERSLEY; ATKINSON, 1995), apresentamos o conceito de evento de formação, mostrando como a formação pode ser descrita, considerando a univocidade de cada aqui e agora e analisando as ações, os tópicos e a configuração de papéis de mais e menos experientes dos participantes.

Nas próximas seções, apresentamos as concepções teóricas que embasam este trabalho. Primeiramente, apresentamos a noção de racionalidade técnica e prática, segundo a visão de Pérez Gomes (1995) e, posteriormente, discutimos os conceitos de conhecimento na ação e reflexão na ação, de Schön (2000), e as propostas de formação de Nóvoa $(1995 ; 2007)$, refletindo sobre como as orientações dos autores podem servir como paradigma de formação em pesquisas qualitativas de cunho etnográfico. Na seção 4, apresentamos a instituição que foi cenário da pesquisa, o processo de geração dos dados etnográficos, bem como os procedimentos de análise adotados. Na seção 5, apresentamos e discutimos dois dados etnográficos de interações entre professores, representativos da coleção de 107 dados etnográficos gerados em observação-participante no ano de 2012 em um instituto cultural brasileiro, localizado em um país latino-americano, e analisamos como ambos se configuram em eventos de formação. De modo abrangente, eventos de formação são momentos propícios para aprender a ensinar, e, a partir de dados 
gerados com professores de português como língua adicional ${ }^{2}$, defendemos que tais eventos se constituem na interação entre os participantes em torno de um tema relacionado a práticas de sala de aula, possuem caráter técnico-prático, podem ser observados nas ações desempenhadas e nas narrativas de experiências vividas.

\section{TEORIA E PRÁTICA NA FORMAÇÃO DE PROFESSORES}

Para Pérez Gómez (1995), há duas abordagens distintas nas intervenções educativas, sobretudo, nas atividades docentes, focalizando o profissional: primeiramente, o professor é um técnico-especialista, que trabalha rigorosamente baseado em regras derivadas do conhecimento científico, e, por outro lado, um "prático autônomo, como artista que reflete, que toma decisões e que cria durante a sua própria ação" (PÉREZ GÓMEZ, 1995, p. 96). Ambas as concepções estão baseadas em linhas de racionalidade distintas: a técnica e a prática.

A abordagem de formação de professores baseada na racionalidade técnica pressupõe que a atividade profissional seja instrumental, baseada na resolução de problemas, mediante o cumprimento de orientações teóricas e aplicação de técnicas cientificamente comprovadas. Nessa perspectiva, os professores enfrentam os problemas de sua prática usando conhecimentos e princípios advindos da pesquisa, o que sugere uma hierarquia entre profissionais e produtores de conhecimento.

A racionalidade técnica impõe, pela própria natureza da produção do conhecimento, uma relação de subordinação dos níveis mais aplicados e próximos da prática aos níveis mais abstratos de produção do conhecimento, ao mesmo tempo que as condições para o isolamento dos profissionais e para a sua confrontação corporativa. (PÉREZ GÓMEZ, 1995, p. 97)

Por outro lado, a racionalidade prática busca superar a relação que a racionalidade técnica estabeleceu entre o conhecimento científico-técnico e a prática de sala de aula. O modelo prático parte da análise das práticas dos professores e do modo como enfrentam os problemas que a vida escolar traz. A complexidade de tais

2 Adotamos o termo língua adicional, ao invés de língua estrangeira, com base no documento Teaching Additional Languages, do International Bureau of Education/UNESCO (JUDD et al, 2001). Para os autores do documento, a escolha do termo "adicional" em lugar de "estrangeira" enfatiza que nenhuma língua é inferior ou superior à outra, nem tampouco deve ser entendida como substituta da primeira língua de um estudante. Desse ponto de vista, a opção privilegia a perspectiva do usuário, que, ao aprender e usar essa língua, para a realização dos propósitos sociais e interlocuções em que se engajam, a adiciona a outras línguas que já tenha em seu repertório. (SCHLATTER, GARCEZ, 2012). 
práticas está, segundo Pérez Gómez (1995), no modo como os professores usam o conhecimento científico, resolvem situações incertas ou desconhecidas, elaboram e modificam rotinas, na experimentação de hipóteses de trabalho, na utilização de técnicas e instrumentos conhecidos e na recriação de estratégias e inovação de procedimentos e recursos. Nessa perspectiva, o professor é um sujeito social que interfere em um meio ecológico complexo, psicossocial, mutável e defronta-se com problemas oriundos da prática, desafios que podem estar relacionados com situações individuais de aprendizagem ou com comportamentos dos grupos com os quais convive.

Todos os elementos que compõem o ecossistema dos cenários escolares requerem de todos os envolvidos, mas dos professores de maneira central, um tratamento singular, que leva em conta as situações complexas específicas, de caráter individual ou coletivo e com características contextuais e históricas do grupo social de professores e de turmas de alunos.

A vida quotidiana de qualquer profissional prático depende do conhecimento tácito que mobiliza e elabora durante a sua própria ação. Sob pressão de múltiplas e simultâneas solicitações da vida escolar, o professor ativa os seus recursos intelectuais [...] (conceitos, teorias, crenças, dados, procedimentos, técnicas), para elaborar um diagnóstico rápido da situação, desenhar estratégias de intervenção e prever o curso futuro dos acontecimentos. [...] A maioria dos recursos intelectuais que se ativam na ação são de caráter tácito e implícito. (PÉREZ GÓMEZ, 1995, p. 102-103)

Conforme veremos mais adiante, os dados que analisamos sugerem que as fronteiras entre a racionalidade técnica e a prática talvez não sejam tão claras. O que se observa é que os eventos em que a formação está relacionada à prática dos participantes também apresentam aportes técnicos, caracterizando, assim, um entrelaçamento entre as duas perspectivas. Apesar de ser uma taxonomia produtiva para a reflexão que empreendemos neste trabalho, o modo como Pérez Gómez (1995) apresenta o tema parece dar um status autônomo a cada uma das racionalidades, entendimento talvez construído sem o amparo de dados concretos. Essa é uma das razões pela qual advogamos pela adoção da perspectiva etnográfica nos estudos sobre formação de professores. Ao trazer a perspectiva do participante para a construção de eventos de formação, buscamos analisar se e de que modo os fazeres técnicos e práticos se tornam relevantes para os professores nas suas práticas profissionais. Como veremos nos dados analisados aqui, tanto a racionalidade prática como a técnica são mobilizadas e se inter-relacionam, o que sugere que uma perspectiva de análise ancorada em uma racionalidade técnico-prática é produtiva para estudar cenários de formação de professores. 
A formação profissional por um viés integrador da técnica e da prática encontra profundidade de análise no trabalho de Schön (2000), que propõe como modelo de formação o paradigma do profissional reflexivo, segundo o qual a formação pode ser entendida como um processo de reflexão-na-ação ou diálogo reflexivo com situações problemáticas concretas a partir do conbecimento-na-ação. De acordo com o autor, conbecimento-na-ação trata do saber fazer, da ação inteligente orientadora de toda atividade humana, e é construído, mesmo que por esquemas automáticos ou rotineiros, a partir da experiência ou reflexões passadas. Neste caso, o conhecimento está relacionado ao saber fazer e não necessariamente ao saber explicar o que se faz, sendo essas capacidades intelectuais distintas. A primeira envolve um tipo de conhecimento primário que supõe uma espécie de diálogo com as situações problemáticas para intervenções concretas; a segunda caracteriza-se por um metaconhecimento na ação.

Schön (2000) argumenta que, em toda ação inteligente na qual nos engajamos, conhecimentos são mobilizados e revelam-se por meio do caráter procedimental de nosso desempenho: "uma variante poderosa e esotérica do tipo mais familiar de competência que todos nós exibimos no dia a dia, em um sem número de atos de reconhecimento, julgamento e performance habilidosa" (SCHÖN, 2000 , p. 29, grifo do autor). Por meio da observação e reflexão sobre nossas ações se faz possível descrever o saber tácito implícito nelas. As descrições do conbecimentona-ação configuram-se como construções que explicitam simbolicamente um tipo de inteligência, primariamente tácito: "conhecer sugere a qualidade dinâmica de conbecer-na-ação, a qual, quando descrevemos, convertemos em conbecimento-na-ação" (SCHÖN, 2000, p. 32).

A reflexão-na-ação significa pensar sobre o que se está fazendo ao mesmo tempo em que se faz: "pensamos retrospectivamente sobre o que fizemos, de modo a descobrir como nosso ato de conbecer-na-ação pode ter contribuído para um resultado inesperado" (SCHÖN, 2000, p. 32). Refletir na ação pode supor rigor, sistematização e distanciamento, mas principalmente "a riqueza da captação viva e imediata das múltiplas variáveis intervenientes e com a grandeza da improvisação e criação" (PÉREZ GÓMEZ, 1995, p. 104). Um profissional flexível e aberto às complexidades da interação prática tem na reflexão-na-prática o melhor instrumento de aprendizagem: "No contato com a situação prática, não só se adquirem e constroem novas teorias, esquemas e conceitos, como se aprende o próprio processo dialético da aprendizagem" (PÉREZ GÓMEZ, 1995, p. 104).

Ao caracterizar a reflexão-na-ação como um conjunto de ações observável, Schön (2000) reconhece que os momentos de reflexão raramente são claros e não 
são facilmente relacionáveis, e as experiências podem ser as próprias interpretações levadas a cabo. Conhecer e refletir na ação não apresentam fronteiras claras, pois são processos interdependentes que se distinguem sutilmente. A cada nova tarefa as ações são ajustadas ativando, momento a momento, um repertório de experiências e memórias.

Com base no paradigma da reflexão-na-ação, Nóvoa (1995) propõe que a formação de professores pode se dar em três modalidades: a) desenvolvimento pessoal dos sujeitos; b) desenvolvimento profissional; e c) desenvolvimento organizacional da escola. $\mathrm{O}$ desenvolvimento pessoal dos sujeitos entende a formação como estímulo a uma atitude crítico-reflexiva, que promova meios para "dinâmicas de autoformação participada" (NÓVOA, 1995, p. 25). Estar em formação significa, nessa modalidade, entrega pessoal, trabalho livre e criativo com vista à construção de uma identidade pessoal e profissional. Sendo o professor a pessoa, parte integrante da pessoa é ser professor. Para o autor, a formação não se constrói por acúmulos de conhecimentos de ordem técnica, mas por meio de um processo constante de reflexividade sobre as práticas juntamente com a construção da identidade pessoal. Assim, a formação valoriza o saber da experiência e está diretamente atrelada ao local e à vida dos profissionais, entendendo o conhecimento como um processo ativo construído ao longo da vida, não necessariamente produzido somente em nível formal, como nas licenciaturas ou em treinamentos específicos, por exemplo. A proposta de Nóvoa (1995) aponta que trocar experiências e saberes consolida espaços de formação mútua, nos quais cada professor pode ser "chamado a desempenhar, simultaneamente, o papel de formador e formando." (NÓVOA, 1995, p. 26). Nessa modalidade, o diálogo entre professores é fundamental no processo de formação: encontros dialogados possibilitam consolidar saberes emergentes da prática profissional e constituem-se em um fator decisivo de socialização profissional e afirmação de valores próprios de ser um profissional professor.

A segunda modalidade de práticas de formação de professores referida por Nóvoa (1995) privilegia o desenvolvimento profissional e toma como referência as dimensões coletivas para a independência profissional e a consolidação da profissão como autônoma em produzir saberes e valores. Nóvoa (1995) apregoa que a formação deve estimular o desenvolvimento profissional favorecendo a autonomia em cada contexto de atuação.

É preciso investir positivamente nos saberes de que o professor é portador, trabalhando-os de um ponto de vista teórico e conceitual. Os problemas da prática profissional docente não são meramente instrumentais; todos eles comportam situações problemáticas que obrigam a decisões num terreno de grande complexidade, incerteza, singularidade e de conflito de valores (SCHÖN, 1990). As situações que os professores são obrigados a enfrentar (e a 
resolver) apresentam características únicas, exigindo, portanto, respostas únicas: o profissional competente possui capacidades de autodesenvolvimento reflexivo. (NÓVOA, 1995, p. 27, grifos no original)

Segundo o autor, tais práticas de formação opõem-se ao que se tem feito tradicionalmente desde a pedagogia científica. Esta tem desvalorizado os repertórios de saberes que os professores construíram ao longo de suas vidas, impondo o saber dito "científico" (NÓVOA, 1995, p. 27), numa lógica guiada pela racionalidade técnica sempre oposta "ao desenvolvimento de uma práxis reflexiva" (NÓVOA, 1995, p. 27). A posição do autor não despreza o conhecimento técnico científico produzido nas instituições de pesquisa, mas propõe que se planeje a formação a partir das práticas locais.

A terceira modalidade referida por Nóvoa (1995) trata do desenvolvimento organizacional, que entende a escola como espaço integral de formação. Para o autor, formação tem a ver com transformação e mudança, e isso significa transformar e mudar práticas pedagógicas e também organizações escolares e seu funcionamento. Assim, formação pode ser vista como um investimento educativo dos projetos políticos pedagógicos.

Para a formação de professores, o desafio consiste em conceber a escola como um ambiente educativo, onde trabalhar e formar não sejam atividades distintas. A formação deve ser encarada como um processo permanente, integrado no dia a dia dos professores e das escolas, e não como uma função que intervém à margem dos projetos profissionais e organizacionais. (NÓVOA, 1995, p. 29)

Como veremos mais adiante, nos eventos de formação analisados neste trabalho, no contexto estudado, os participantes constroem essas diferentes modalidades de formação por meio do compartilhamento de conhecimentos relacionados ao ensino de português como língua adicional e propõem tanto transformações pessoais e profissionais quanto institucionais.

\section{UM OLHAR ETNOGRÁFICO PARA AS PRÁTICAS DE FORMAÇÃO DE PROFESSORES}

O instituto no qual este trabalho foi realizado é uma instituição privada que contava, no período de geração de dados, com 12 professores de língua portuguesa, sendo quatro deles formados na área de Letras e outros em outras áreas como Geografia, Turismo e Administração. Todos os professores, equipe diretiva e funcionários consentiram por escrito em participar da pesquisa. Os professores 
ministram aulas desde o nível básico até o avançado e colaboram em atividades de difusão cultural como sessões de cinema brasileiro e festas de Carnaval. O instituto é o único posto aplicador do exame Celpe-Bras ${ }^{3}$ no país onde está localizado e alguns dos professores participantes da pesquisa também são aplicadores do exame.

Com base nos princípios etnográficos de estranhamento e reflexividade (HAMMERSLEY; ATKINSON, 1995), um dos autores deste trabalho (COSTA, 2013) empreendeu o trabalho de campo com uma observação participante, que consistiu em acompanhar por dois meses as rotinas dos professores, fora de sala de aula, tomando notas de campo e registrando, em fotos e gravações de áudio, interações entre os participantes. Os materiais gerados em campo foram posteriormente convertidos em diários de campo e transcrições. Os encontros dos professores observados ocorreram em diferentes momentos e ambientes, sendo os intervalos entre as aulas e as reuniões pedagógicas os momentos de maior ocorrência dos eventos de formação. A análise dos dados se deu a partir de repetidas leituras dos diários de campo e das transcrições tendo como base a noção de evento social (RIBEIRO; GARCEZ, 2006).

Para Ribeiro e Garcez (1998), evento ou evento social é

[...] uma definição social da atividade de fala que se desenvolve na situação dependendo das oportunidades e restrições à interação proporcionadas pela mudança dos participantes e/ou objeto da interação. Os eventos se desenvolvem ao redor de um tópico ou no máximo de um âmbito limitado de tópicos e se distinguem por suas estruturas sequenciais. Eles são marcados por rotinas de abertura e fechamento estereotipadas e, portanto, reconhecíveis. (RIBEIRO, GARCEZ, 1998, p. 261-262)

Para os autores, um evento é determinado pelo cumprimento de certas normas e ganham diferentes arranjos em cada nova interação. Assim, dois professores reunidos discutindo uma reformulação no sistema de avaliação em uma escola segue determinados padrões de fala, ao passo que propor à coordenadora pedagógica as implementações de novas formas de avaliar os alunos, mesmo que trate do mesmo tema e envolva os mesmos participantes no mesmo local, pode envolver outras maneiras de abrir e fechar o evento. A partir da análise dos dados relatada no presente artigo, os eventos, nos quais foi possível identificar a formação dos professores como parte integrante dos propósitos desempenhados pelos participantes, foram descritos como eventos de formação.

3 O Celpe-Bras, Certificado de Proficiência de Língua Portuguesa para Estrangeiros, é outorgado pelo Ministério da Educação do Brasil a candidatos estrangeiros. O exame certifica os níveis Intermediário, Intermediário Superior, Avançado e Avançado Superior, e caracteriza-se por uma perspectiva de uso da linguagem para o desempenho de ações no mundo com um propósito social. As tarefas que compõem as partes escrita e oral utilizam materiais autênticos e integram leitura, escrita, compreensão e produção oral, e não testam gramática e vocabulário separadamente. 
Adotamos a noção de evento como foco analítico, já que, em termos de formação de professores, conforme explicado anteriormente, entendemos que os problemas não existem na prática ${ }^{4}$, mas sim em situações problemáticas, ou seja, casos únicos que não se enquadram, a priori, em categorias genéricas já identificadas em modelos teóricos (PÉREZ GÓMEZ, 1995). A opção por descrever eventos sociais nos quais os professores do instituto estudado (re)atualizam os significados sobre sua prática também se baseia na importância de colocar a figura do professor no centro das ações de formação, conforme a discussão apresentada na seção anterior.

Após reunir 107 eventos em que formação era relevante para o que os participantes estavam fazendo, chegou-se a 30 eventos que mostraram um tipo de organização recorrente e que caracterizamos como evento de formação. Um evento de formação se organiza em torno de ações que os participantes desempenham conjuntamente: apresentar modelos e estratégias de ensino; relatar experiências de sala de aula; responder a perguntas sobre questões de sala de aula; oferecer ajuda quando solicitada. O tópico tratado nas interações em eventos de formação tem relação com as práticas de sala de aula e constitui o foco específico de ensino em pauta entre os participantes. Os tópicos mais recorrentes foram: estratégias para o ensino de gramática; elaboração de instrumentos de avaliação; e elaboração de materiais didáticos.

A formulação do conceito de evento de formação descreve os padrões de formação que acontecem no instituto, os quais são orientados pela combinação de ações com tópicos de relevância para a prática de sala de aula. $\mathrm{O}$ argumento central, no entanto, é de que um evento de formação, além de ser em si um momento em que os participantes se orientam para aprender com o outro, é um momento que tem como foco o ensino, já que as ações e os tópicos orientam-se pela necessidade de ensinar, em uma lógica de racionalidade técnico-prática ${ }^{5}$. Dito de outra forma: aprender a ensinar certos conteúdos é o propósito geral dos eventos descritos neste

4 Adotamos aqui uma perspectiva de prática social conforme os estudos de Bourdieu (1977), segundo os quais uma prática é um conjunto de ações imbuídas de história e constituído pelas disposições do habitus. Portanto, não podemos assumir que uma prática seja em si um problema, mas que, sim, na contingência das ações há situações problemáticas que são interpretadas desse modo pelos praticantes (sujeitos da prática).

5 Chamamos a atenção para o fato de que, na definição do que é um evento de formação, os tópicos são uma combinação do que poderíamos chamar de "conteúdos técnicos" (gramática, avaliação e materiais didáticos) e as ações que designam o uso desses conhecimentos nas práticas de sala de aula (apresentar, modelar, relatar, elaborar). Isso aponta para uma caracterização do evento numa perspectiva de racionalidade técnico-prática, ao invés de racionalidades técnica e prática separadamente, conforme proposto por Pérez Gómez (1995) e discutido anteriormente. Embora não seja objetivo deste trabalho discutir a distinção entre conhecimento técnico e conhecimento prático, consideramos importante chamar a atenção para essa decisão, fruto da análise dos dados gerados, e reconhecer que essa questão merece aprofundamento em futuros trabalhos. 
trabalho. Além disso, todas as ações dos participantes aqui analisadas caracterizamse pela narratividade: articular e apresentar o que consideram uma experiência relevante para o tópico em foco é o modo de sustentar as ações que constroem o evento de formação. Isso quer dizer que, em um evento de formação, recorrer às narrativas do vivido é parte constitutiva das ações dos participantes.

\section{EVENTOS DE FORMAÇÃO: PRÁTICAS SITUADAS DE FORMAÇÃO DE PROFESSORES}

Conforme dito anteriormente e como poderemos ver nos dados analisados a seguir, um evento de formação caracteriza-se pela resolução de problemas e compartilhamento de experiências de prática pedagógica relacionados a uma gama de tópicos específicos tornados relevantes pelos participantes, tais como modos de explicar uma regra gramatical, de organizar atividades em sala de aula ou de elaborar um instrumento de avaliação. Um evento de formação se organiza em torno de ações que os participantes desempenham conjuntamente: apresentar modelos e estratégias de ensino; relatar experiências de sala de aula; responder perguntas sobre questões de sala de aula; oferecer ajuda quando solicitada ${ }^{6}$. O tópico tratado nas interações em eventos de formação tem relação com as práticas de sala de aula e constitui o foco específico de ensino em pauta entre os participantes. Os tópicos mais recorrentes foram: estratégias para o ensino de gramática; elaboração de instrumentos de avaliação; elaboração de materiais didáticos.

O dado que apresentamos a seguir ocorre na cozinha do instituto. Por ser um espaço para atividades variadas, como conversar, comer e também discutir sobre gramática, avaliação e métodos, quem estiver presente pode participar. O tópico para discussão, no dado abaixo, são explicações de gramática, com base no uso do livro didático. No excerto, Lúcia ${ }^{7}$ procura responder a Priscila dúvidas sobre o Infinitivo Pessoal, com a ocasional contribuição de Alberto. Bianca, que está sentada sobre a mesa, ao lado de Lúcia, acompanha os colegas. Priscila começa a folhear e procurar algo entre as folhas do fichário. Bianca e Alberto as observam ${ }^{8}$.

\footnotetext{
6 Garcez e Salimen (2011) caracterizam "'Pedir ajuda' como a ação de um participante direcionar um turno de fala a outro pedindo ajuda para fazer algo que não consegue ou não quer fazer sozinho. $\mathrm{O}$ outro participante, então, pode prover ou não a ajuda solicitada". Entende-se 'oferta de ajuda' como uma ação em que "um participante oferece ajuda sem que a ajuda tenha sido solicitada". (GARCEZ; SALIMEN, 2011, p. 99)

7 Todos os nomes utilizados no presente artigo são pseudônimos.

8 As transcrições utilizadas neste trabalho seguem as seguintes convenções: (.) pausa de até um segundo; (..) pausas de mais de 1 segundo, (...) pausas longas, acima de três segundos. Entre parênteses, em itálico constam descrições da cena.
} 
Excerto I. Vamos ver então as dúvidas da Priscila para que todos aprendam

\begin{tabular}{|c|c|c|}
\hline 1 & Bianca: & Priscila [.] tem alguém te procurando (Priscila volta para a cozinba, \\
\hline 2 & & aproxima-se e cumprimenta Lúcia. As duas se debruçam sobre o material) \\
\hline 3 & Lúcia: & vamos ver \\
\hline 4 & Bianca: & vamos ver então as dúvidas da Priscila para que todos aprendam \\
\hline 5 & Priscila & (dirigindo o olbar para Lúcia) lembra que tu tava me mostrando aqui [.] a \\
\hline 6 & & história de [.] por não ter o sujeito antecedendo aqui o verbo no \\
\hline 7 & & infinitivo [.] então ele não é flexionado de acordo [.] não é \\
\hline 8 & Lúcia: & uhum \\
\hline 9 & Priscila: & muito bem [.] aqui por exemplo elas não entraram porque não tinham \\
\hline 10 & & convite [.] aí é aquela mesma história né [..] por não ter convite elas [...] \\
\hline 11 & & como era aqui [...] (Ambas observam a frase escrita a lápis em uma folba \\
\hline 12 & & de caderno solta no fichário) \\
\hline 13 & & como é que transforma aqui essa frase por exemplo [.] elas não entraram \\
\hline 14 & & por não ter convite [.] seria assim [..] seria isso \\
\hline 15 & Lúcia: & aham [.] a frase era eles não entraram porque não tinham convite \\
\hline 16 & Priscila: & certo [.] elas não entraram por não ter convite \\
\hline 17 & Lúcia: & aí a gente achou a conjunção [.] e a conjunção virou \\
\hline 18 & Priscila: & aí lógico [.] se eu coloco a oração no início não é [.] então por não ter \\
\hline 19 & & convite elas não entraram \\
\hline 20 & Lúcia: & uhum \\
\hline 21 & Priscila: & né [..] eu poderia ter por não terem convite elas não entraram (Lúcia \\
\hline 22 & & observa, Bianca e Alberto acompanbam atentamente) \\
\hline 23 & Priscila: & porque eu tava olhando essa meleca aqui \\
\hline 24 & Lúcia: & nas orações com infinitivo [...] (lê na follha) \\
\hline 25 & Priscila: & sujeito expresso [...] (acompanba a leitura) \\
\hline 26 & & (Lisiane entra. Lúcia e Priscila seguem lendo as explicações no \\
\hline 27 & & material fotocopiado. Bianca fala com Lisiane) \\
\hline 28 & Lúcia: & elas não puderam entrar porque não tinham convite \\
\hline 29 & Priscila: & aí não é o mesmo exemplo? (mexendo nas folhas) \\
\hline 30 & Lúcia: & elas não puderam entrar porque $[\ldots]$ não $[\ldots]$ ai $[$.$] por não terem con [\ldots]$ \\
\hline 31 & & ai ai [.] agora eu não sei (Lúcia mexe os ombros, movimenta o corpo, \\
\hline 32 & & direciona o olhar para Alberto) \\
\hline 33 & Priscila: & pois é [.] também me confundi \\
\hline
\end{tabular}




\begin{tabular}{|c|c|c|}
\hline 34 & Lúcia: & (lendo rápido) por não ter convite elas não puderam entrar [...] elas não \\
\hline 35 & & puderam entrar porque elas não tinham convite [..] elas não puderam \\
\hline 36 & & entrar por que não [..] (Priscila lê uma explicação em uma página do \\
\hline 37 & & material fotocopiado) \\
\hline 38 & Lúcia: & ai [.] não entendi não [.] essa aí eu não sei agora vamos ter que perguntar \\
\hline 39 & & (Lúcia olba para Alberto) \\
\hline 40 & Alberto: & qual é \\
\hline 41 & Bianca: & tu tinha me ensinado isso Lu (Lúcia lê novamente) \\
\hline 42 & Lúcia: & mas essa aqui ó [..] por não ter convite elas não puderam entrar e por não \\
\hline 43 & & terem convite elas não puderam entrar \\
\hline 44 & Alberto: & é o mesmo sujeito né \\
\hline 45 & Lúcia: & mas por que um é ter e a outra é terem \\
\hline 46 & Alberto: & aí é facultativo né [...] (Silêncio, Bianca, Lúcia e Priscila olham a frase \\
\hline 47 & & no material. Lisiane, que aquece algo no microondas, também observa) \\
\hline 48 & Alberto: & quando o sujeito é o mesmo nos dois verbos aí ele fica facultativo \\
\hline 49 & Bianca: & eu posso tanto usar por não ter e por não terem que significa o \\
\hline 50 & & mesmo \\
\hline 51 & Alberto: & isso [..] por exemplo [...] \\
\hline 52 & Lúcia: & $\mathrm{mmmmm}$ \\
\hline 53 & Alberto: & elas saíram por não estarem se sentindo bem ou elas saíram por não \\
\hline 54 & & estar se sentindo bem \\
\hline 55 & Lúcia: & ok \\
\hline 56 & Alberto: & porque é o mesmo sujeito \\
\hline 57 & Bianca: & isso por que é o mesmo sujeito das duas \\
\hline 58 & Alberto: & é [.] exatamente \\
\hline 59 & Priscila: & que é o mesmo sujeito [.] tô entendendo \\
\hline 60 & Lúcia: & (incompreensível) \\
\hline 61 & Priscila: & agora [.] por exemplo [..] (interrompe para observar as frases no material) \\
\hline 62 & Bianca: & é a mesma história daquilo que a Sônia nos passou que os presentes \\
\hline 63 & & aplaudiram \\
\hline 64 & Lúcia: & (em sobreposição) aqui poderia ser assim ó por \\
\hline 65 & Bianca: & ou convido os presentes a aplaudirem \\
\hline 66 & Alberto: & aplaudirem \\
\hline 67 & Lúcia: & não terem convite também poderia ser, os dois \\
\hline 68 & Alberto: & aplaudirem [...] não não é porque o sujeito é diferente \\
\hline
\end{tabular}




\begin{tabular}{|c|c|l|}
\hline 69 & Lúcia: & aqui são dois sujeitos \\
\hline 70 & Priscila: & (para Lúcia) então o segundo caso quando é um sujeito a transformação \\
\hline 71 & & é facultativa aqui \\
\hline 72 & Lúcia: & é \\
\hline 73 & Priscila: & certo [.] com o mesmo verbo \\
\hline 74 & Lúcia: & e essa aqui é diferente porque são dois sujeitos com duas orações \\
\hline 75 & & diferentes (Priscila folbeia o material em busca de algo) \\
\hline 76 & Priscila: & aqui [...] \\
\hline 77 & Lúcia: & pode ser para ter certeza necessitamos informações ou para termos \\
\hline 78 & & certeza precisamos de mais informação [.] aqui ó (lendo e apontando \\
\hline 79 & & o dedo para o material) em todas as frases abaixo o uso é opcional \\
\hline 80 & Priscila: & então [.] elas saíram da sala sem [...] \\
\hline 81 & Alberto: & uhm \\
\hline 83 & Priscila: & sem pedir licença \\
\hline 84 & Lúcia: & ou sem pedirem licença \\
\hline & & $\begin{array}{l}\text { Diário 3, p. 15 e 16: Observação participante (notas de campo, gravação em áudio e fotos), } \\
14 / 02 / 12 .\end{array}$ \\
\hline
\end{tabular}

Priscila apresenta sua dúvida para Lúcia, apontando para uma folha com frases escritas e com a apostila (fotocópia do livro Avenida Brasil 2 - Lima et al, 1992) aberta sobre a mesa. Priscila descreve qual é sua dúvida (linhas 5 a 7) e direciona uma pergunta para Lúcia (linha 7), que por sua vez observa atentamente. As duas professoras leem duas frases idênticas, uma delas com o infinitivo pessoal, e procuram inferir qual é a razão pela dupla possibilidade de flexão do mesmo verbo. A informação "sujeito expresso" não é interpretada imediatamente como a resolução para a dúvida. As duas frases estão tanto no livro didático como na folha que Priscila traz consigo. No material há a descrição da regra.

O espaço de tempo entre a chegada de Lúcia à cozinha e o início do período de aulas das $16 \mathrm{~h}$ e a atividade na qual se engajam os participantes nesse período, que inicia com a formulação de uma dúvida sobre como explicar a regra gramatical do infinitivo pessoal (linhas 9 a 14) e segue com diferentes propostas de explicação e de exemplificação para resolver a questão, constroem o que estamos chamando de evento de formação: uma ocorrência em uma faixa de tempo, envolvendo dois ou mais participantes, na qual os propósitos da interação entre eles dizem respeito a resolver uma questão relevante para a sala de aula. Esses eventos são, assim, potenciais formadores de professores no instituto onde os dados foram gerados. 
A base para afirmar que há potencialidade de formação (embora usemos diretamente o termo "formação") está no fato de que os eventos apontam para uma prática de aprender a ensinar. As ações que as participantes desempenham se centralizam nas perguntas de Priscila a Lúcia, o que caracteriza um pedido de ajuda nesse caso, visto que Priscila necessita formular a explicação em aula. Lúcia, por sua vez, procura prover respostas às inquietações da colega, com olhares direcionados para a folha manuscrita e para a apostila. Tanto o comentário inicial de Bianca, "Vamos ver então as dúvidas da Priscila, para que todos aprendam" (linha 4), como a introdução do problema por Priscila, "Lembra que tu tava me mostrando aqui a história de por não ter o sujeito antecedendo aqui o verbo no infinitivo, então ele não é flexionado de acordo, não é?" (linhas 5 a 7), e ainda o comentário "Tu tinha me explicado isto, Lu" (linha 41), feito mais adiante por Bianca, retomam outras situações semelhantes vivenciadas por elas anteriormente, sinalizando que esses eventos fazem parte das práticas sociais nesse instituto. Trocam-se relatos de experiências e explicações e, nesses eventos, pode-se aprender com a dúvida e o conhecimento do outro, o que confere centralidade para a experiência na formação de professores.

Nesse evento, Lúcia e Priscila estão reunidas em torno do material de quinto nível (intermediário superior), e Priscila tem uma demanda que gera um pedido de ajuda: como explicar o uso do infinitivo pessoal. Sua preocupação é com uma regra que possa esclarecer para os alunos como utilizar essa forma gramatical da língua portuguesa, mas também que ela mesma entenda tal regra. O trabalho interacional das duas professoras consiste em uma análise conjunta de frases soltas, que são aquelas que o livro traz, visando à resolução de um problema prático: a explicação da matéria em sala de aula. Bianca, Lisiane (que entra na cozinha depois que a explicação se inicia) e Alberto observam as duas colegas e mais adiante se engajam na resolução do problema. Pelo fato de a pergunta ser dirigida à Lúcia, e ela responder a essa solicitação, a ela é atribuído o status de mais experiente no quinto nível, mas isso não significa que ela também não possa ter dúvidas, como de fato ocorre. A orientação de olhar de Lúcia para Alberto é interpretada como um pedido de ajuda, que ele atende (linhas 38 a 40). A explicação de um terceiro participante é assim autorizada para a resolução do problema em foco.

O conteúdo apresentado no livro didático e a iminência de ter que ensinálo originam e justificam o evento de formação. A partir do que o livro propõe, a professora Priscila procura Lúcia, pois o livro não traz orientação suficiente que possibilite entender de uma maneira clara como explicar o conteúdo gramatical específico. Esse fato sinaliza que a formação continuada acontece a partir do que se 
torna relevante no aqui e agora das práticas docentes, o que inclui, nesse caso, o livro didático e a linguagem usada por suas autoras. Certos tópicos de gramática oferecem dificuldades de compreensão aos participantes, especialmente, se desvinculados de seu uso. As professoras, nesse evento, lidam com o que o livro propõe, e é com isso que o aluno também se confrontará. O propósito em questão é o ensino exitoso de um conteúdo gramatical, e, para tratar disso, Lúcia tem experiência para poder ajudar quem ainda não teve tais experiências, conforme lembra Bianca (linha 41). Com a dúvida ainda não resolvida, outros participantes são autorizados a intervir, como é caso de Alberto, que contribui com algumas explicações: "quando o sujeito é o mesmo nos dois verbos aí ele fica facultativo" (linha 48).

O excerto analisado compõe uma das ocorrências observadas nos intervalos entre uma aula e outra no instituto, em um dia de aulas habitual, configurando um evento de formação emergente das contingências do dia a dia dos professores. A seguir passamos a apresentação e análise de um dado gerado em uma reunião pedagógica do mesmo instituto, lócus para a ocorrência de eventos de formação planejados institucionalmente. Como veremos, de modo complementar à ação formativa projetada pela coordenação pedagógica, a contingência das interações provê relevância aos eventos segundo a perspectiva dos participantes e de acordo com sua experiência no tópico. A experiência funciona como um critério tácito na formação no instituto, isto é, em certas ocasiões algum participante pode orientar o trabalho dos outros visando à oportunidade de formação que participantes menos experientes possuem em um determinado tópico.

No excerto a seguir, os participantes estão em uma reunião pedagógica. Sônia propõe que a reunião seja em pequenos grupos, pois há demandas a serem resolvidas, especialmente relacionadas à adoção do livro didático. $\mathrm{O}$ instituto adotou por muitos anos o livro Avenida Brasil 1 e 2, o qual, com sua divisão de doze lições em cada um, em um total de vinte e quatro, possibilitou a divisão do curso em seis níveis, cada um com quatro lições. Com a adoção do Novo Avenida Brasil 1, 2, 3, a estrutura dos níveis mudou, e cada um passou a ter apenas três lições até o quarto nível e quatro lições nos níveis finais. Além disso, a nova edição do Avenida Brasil modificou a disposição de algumas lições, o que acarretou a necessidade de readequação das provas que os professores utilizavam. É nesse contexto que é proposta a pauta da reunião: revisão e reelaboração de instrumentos de avaliação. 
Excerto II. Então, gente, vamos nos dividir

\begin{tabular}{|c|l|}
\hline 1 & Sônia propõe que os professores se dividam em grupos para trabalhar com as \\
\hline 2 & provas: "então, gente, vamos nos dividir. Lisiane, você começa pegando uma \\
\hline 3 & folha pra você anotar as respostas, todas as respostas possíveis, começa \\
\hline 4 & fazendo isto e vai verificando (inaudivel), Karen e Flávia vão trabalhar o quê \\
\hline 5 & com os elementos do Celpe pra (inaudivel) as provas". Jaqueline e Augusto \\
\hline 6 & também são designados como um grupo. Jaqueline e Augusto discutem como \\
\hline 7 & trabalhar. Sônia e Augusto discutem sobre quais itens devem integrar uma \\
\hline 8 & prova escrita de primeiro nível. Caroline segue falando com Alberto e também \\
\hline 9 & com Karen. Sônia está de pé falando com Augusto e Jaqueline. Circula um \\
\hline 10 & cartão de aniversário para uma funcionária, que os professores vão assinando. \\
\hline 11 & Sônia pergunta se Caroline trouxe suas provas. Caroline informa que esqueceu \\
\hline 12 & Há uma profusão de vozes, todos falam ao mesmo tempo. Alguns riem. Sônia \\
\hline 13 & dá instruções a cada um sobre o que fazer na reunião: alguns vão elaborar uma \\
\hline 14 & prova de primeiro nível, outros vão corrigir provas. Sônia circula pelas \\
\hline 15 & carteiras dos professores verificando o que cada um trouxe para determinar \\
\hline 16 & o que irão fazer. Designa Flávia e Karen para trabalharem com elementos \\
\hline 17 & provocadores do Celpe-Bras. Pergunta a Caroline se ela já conhece os \\
\hline 18 & elementos, e como essa responde que não, Sônia solicita que trabalhe com \\
\hline 19 & Flávia e Karen. Flávia pergunta desde qual edição do Celpe deve trabalhar. \\
\hline 20 & Sônia sugere as mais recentes. Lúcia corrige provas em um canto da sala. \\
\hline & $\begin{array}{l}\text { (Diário 5, p. } 5 \text { - Observação participante (notas de campo, gravação em áudio e fotos) 24/o2/12 - reunião } \\
\text { pedagógica) }\end{array}$ \\
\hline
\end{tabular}

Sônia está gerenciando a reunião e designa pequenos grupos de trabalho para o cumprimento de diferentes tarefas. Sônia pede confirmação a Flávia e Karen sobre o que vão trabalhar, e ela mesma confirma, os elementos provocadores do exame Celpe-Bras (linhas 4 e 5) para utilização destes nas provas orais do instituto. Jaqueline vai trabalhar com Augusto na elaboração de uma prova escrita. Em meio a um clima bastante descontraído de início de reunião, onde conversas paralelas sobre assuntos variados estão se desenvolvendo e o cartão de aniversário de uma

9 Os elementos provocadores do exame Celpe-Bras são os materiais que servem de base para a interação oral que constitui a Parte Oral do exame. Eles são cartões com propostas de temas de conversa entre entrevistador e candidato retirados de meios de comunicação impressos publicados no Brasil. A seleção de cada três elementos para cada candidato deve se dar com base no questionário respondido por ele no ato da inscrição. 
funcionária circula para que todos assinem, Sônia vai gerenciando e designando tarefas. Ela verifica de quais materiais cada um dos professores dispõe, conversa com um e com outro, tira dúvidas de Augusto.

Karen e Flávia trabalham no mesmo grupo, por designação de Sônia, mas não ficarão sozinhas nesse trabalho. Sônia, após verificar que Caroline não trouxe materiais para a reunião, que se depreende tratar de provas escritas dos níveis que ela ensina, designa a professora para trabalhar com as duas colegas. Karen e Flávia têm um trabalho a fazer e uma colega para acompanhá-las. A designação por parte de Sônia tem uma motivação explícita: Caroline não conhece os elementos provocadores do Exame Celpe-Bras (linhas 17 a 20). O trabalho específico desse grupo é analisado a seguir.

$\mathrm{Na}$ reunião dividida em pequenos grupos, em diferentes salas, Flávia, Karen e Caroline reuniram-se na sala 3.

\section{Excerto III. Vou separar os livrinhos com as fotinhos}

\begin{tabular}{|c|l|}
\hline 1 & As três professoras estão ao redor de uma caixa, colocada em cima de uma \\
\hline 2 & cadeira. Elas estão observando elementos provocadores do Celpe-Bras, separam \\
\hline 3 & alguns, tecem comentários rápidos sobre um ou outro elemento. Flávia pega \\
\hline 4 & uma pilha de elementos de dentro da caixa e joga no chão, o que gera um \\
\hline 5 & barulho forte e seco, um estrondo pelo impacto da pilha de elementos feitos de \\
\hline 6 & papel-cartão e o assoalho de madeira, forrado de carpete. As professoras então \\
\hline 7 & se posicionam no chão, de joelhos ou sentadas e se engajam em um trabalho \\
\hline 8 & braçal de separação de elementos provocadores por edição do exame Celpe-Bras. \\
\hline 9 & Às vezes Karen levanta e pega mais elementos de dentro da caixa. Flávia \\
\hline 10 & conta um pouco de sua história como aplicadora do Celpe-Bras. Através dos \\
\hline 11 & elementos, Flávia lembra alguns episódios. Caroline trata os elementos como \\
\hline 12 & "fotinhos", e cantarola enquanto observa os elementos. Caroline se prontifica \\
\hline 13 & a organizar os elementos de 2010 e 2011: "vou separar os livrinhos com as \\
\hline 14 & fotinhos". Karen aprova. Flávia não concorda e aponta para uma pilha de \\
\hline 15 & elementos que também devem ser organizados, o que julga mais urgente. \\
\hline 16 & Karen explica que entre os de 2010 e 2011 há muitos elementos misturados. \\
\hline 17 & Elas procuram elementos pelas edições do exame. Flávia mostra para as colegas \\
\hline 18 & quando encontra algum elemento provocador que alguma colega está \\
\hline 19 & procurando. Flávia demonstra pessimismo em conseguir dar conta de todo \\
\hline 20 & o trabalho ainda hoje. Há muitas pilhas de muitas edições do Celpe. \\
\hline & (Diário 5, p. 9 e 10 - Observação participante 24/o2/12 - reunião pedagógica) \\
\hline
\end{tabular}


Flávia lidera o trabalho e conta episódios sobre as aplicações orais do exame. O material se encontra desorganizado, e é ela quem decide as prioridades. O trabalho de Flávia é cooperativo, pois presta atenção no que as colegas estão fazendo e oferece ajuda quando percebe dúvidas no trabalho das outras. O início do trabalho das professoras centra-se na organização de elementos provocadores. Antes de selecionar, há que organizar. Desse modo, Caroline acaba por ter a oportunidade de manusear e observar o que são elementos provocadores e como o trabalho deve ser realizado. A modalidade de reunião pedagógica em grupos de trabalho não necessariamente tem como meta a formação, mas a formação acontece para participantes como Caroline, que, neste caso, terá seu primeiro contato com um artefato relevante para as reflexões dos professores do instituto. Não cabe neste trabalho aprofundar como o exame Celpe-Bras tem um papel formador decisivo nesse lugar, o que exigiria uma pesquisa com outro foco analítico. No entanto, neste evento de formação, é possível observar que o exame é tacitamente interpretado pelos participantes como um construto de avaliação válido o suficiente para que interfira em suas práticas cotidianas. Toda a atividade é orientada em torno do construto da parte oral do exame. Mesmo que o construto não seja discutido explicitamente, as professoras lidam com o que o exame pressupõe como proficiência oral e com o formato da prova, e sinalizam desejar que tal formato passe a integrar suas práticas de avaliação.

O exame também exerce papel na constituição histórica da professora Flávia como profissional. Ela já é aplicadora da parte oral há muitos anos, e tem muitas vivências nessa função. Relatar a história vivida possibilita a Caroline acesso a um repertório de práticas relevantes para os professores do instituto. Caroline está engajada no trabalho, compreende que a primeira etapa do trabalho se relaciona com organizar conjuntos de elementos provocadores com seus respectivos cadernos de questões, mesmo que a nomenclatura que as outras professoras utilizem se diferencie da sua.

Numa reunião em pequenos grupos de trabalho, relatar experiências é uma prática reconhecida pelos participantes como frutífera para que alguns tenham contato com a história compartilhada do instituto. O compartilhamento das histórias que têm por base as experiências é reforçado por Karen, que, no excerto seguinte, solicita que Flávia dê mais detalhes sobre a história de aplicações do exame CelpeBras no instituto. 
Excerto IV. E desde quando tem os preparatórios, Flávia

\begin{tabular}{|c|c|c|}
\hline 1 & Karen: & e desde quando tem os preparatórios Flávia \\
\hline 2 & Flávia: & ah [..] acho que desde 2000 se não me engano \\
\hline 3 & Karen: & o preparatório [..] \\
\hline 4 & Flávia: & qual [.] o curso preparatório [.] não sei \\
\hline 5 & Caroline: & o curso preparatório os meninos pagam a parte \\
\hline 6 & Karen: & $\operatorname{sim}$ (Estrondo, Flávia joga a caixa de elementos no chão) \\
\hline 7 & Caroline: & e demora quanto tempo \\
\hline 8 & Karen: & duas semanas [.] depende porque tem os cursos de sábado e os cursos \\
\hline 9 & & da semana [.] mas quem dá é a Flávia a Sônia a Jaqueline e o Alberto \\
\hline 10 & & {$[.]$.} \\
\hline 11 & Flávia: & mas eu só comecei a dar o curso do Celpe só depois que ele foi embora. \\
\hline 12 & & eu nunca dava [.] eu sempre morria de preguiça de corrigir tanto texto \\
\hline 13 & & (riem) eu sempre fugia [..] eu escorregava mais que lambari ensaboado \\
\hline 14 & & (Risos) \\
\hline 15 & Karen: & e quem dava [.] a Sônia o Alberto o Roberto \\
\hline 16 & Flávia: & o Roberto [..] \\
\hline 17 & Karen: & a Dina $[\ldots .$.$] o Antônio não dava$ \\
\hline 18 & Flávia: & não sei [...] (Enquanto elas conversam seguem dividindo os elementos, \\
\hline 19 & & que agora começam a se distribuir pelo chão da sala 3, em pequenas \\
\hline \multirow[t]{2}{*}{20} & & pilhas.) \\
\hline & & $\begin{array}{l}\text { (Diário 5, p. } 11 \text { - Observação participante (notas de campo, gravação em áudio e fotos) } \\
24 / 02 / 12 \text { - reunião pedagógica) }\end{array}$ \\
\hline
\end{tabular}

A pergunta de Karen (linha 1) gera uma retomada da história das aplicações a partir da existência dos cursos preparatórios para o exame Celpe-Bras e da experiência de Flávia com o curso (linhas 11 a 13). Os cursos preparatórios são oferecidos no instituto um mês antes da aplicação do exame, e há determinados professores que o ministram. A pergunta de Karen leva Flávia a relatar sua própria história como ministrante de cursos preparatórios e abre espaço para a curiosidade de Caroline de saber mais sobre o funcionamento logístico dos cursos oferecidos pelo instituto. Em eventos como esse as perguntas dos participantes provocam relatos e explicações que, por sua vez, podem gerar novas perguntas. Caroline está em contato com as práticas das duas colegas, com o conhecimento terminológico sobre o exame Celpe-Bras, e também toma conhecimento sobre o significado do exame dentro do instituto, por meio de seus desdobramentos, como os cursos 
preparatórios. Para Flávia e Karen, sua função de formadoras advém da designação de Sônia de colocar Caroline no grupo porque ambas já têm tempo de experiência como examinadoras. A ação de Sônia de colocar Caroline para acompanhar o trabalho de Flávia e Karen revela que há convicção de que o contato com pares mais experientes oferece oportunidade de formação. Karen provoca o relato de Flávia, que, por sua vez, passa a proporcionar a Caroline o contato com a história de preparar para o exame e com o próprio funcionamento do instituto de oferecer curso preparatório e contar com os professores que conhecem o exame para ministrá-lo.

No excerto seguinte, Karen oferece uma explicação sobre a aplicação da parte oral do exame Celpe-Bras, enquanto Flávia se ausenta. Com a volta de Flávia à sala, Karen solicita à colega que observe seu trabalho de explicar para Caroline, tornandose central o papel da experiência de cada uma para organizar suas participações na interação como formadora mais experiente (Flávia), formadora experiente (Karen) colocando à prova seu conhecimento para explicar procedimentos à professora iniciante (Caroline).

Excerto V. Tem a parte escrita e depois tem a parte oral

\begin{tabular}{|c|c|l|}
\hline 1 & Flávia: & eu vou lá trazer minhas pastas (levanta e se dirige a porta) \\
\hline 2 & Karen: & [..] por que tá [.] \\
\hline 3 & Caroline: & a gente vai pegar cada elemento desse aqui e separar por por [.] botar \\
\hline 4 & & os números dos níveis por exemplo [.] \\
\hline 5 & Karen: & é [.] e aí [.] deixa eu te explicar [.] é assim [.] como é feita a prova do \\
\hline 6 & & do Celpe [.] tem a parte escrita e depois tem a parte oral [...] \\
\hline 7 & & então quando você tem [.] a Sônia dá todas as explicações e ela explica \\
\hline 8 & & a gente lê todos os elementos e depois as perguntas \\
\hline 9 & & (Priscila entra na sala e cumprimenta as colegas. Senta-se numa \\
\hline 10 & & carteira que está no meio da sala) \\
\hline 11 & Caroline: & uhum [.] e antes de aplicar a prova (Karen se orienta para Priscila, \\
\hline 12 & & pergunta como ela se sente. Priscila diz que está melhor. Caroline \\
\hline 13 & & também pergunta. Karen conta a Caroline que Priscila passou mal \\
\hline 14 & & ontem) \\
\hline 15 & Karen: & então [.] cada elemento vem um jogo um jogo de elementos e as \\
\hline 16 & & perguntas \\
\hline 17 & Caroline: & vem um jogo de elementos \\
\hline 18 & Karen: & aí nós lemos todas as perguntas e nós pegamos pros alunos dependendo \\
\hline
\end{tabular}




\begin{tabular}{|c|c|c|}
\hline 19 & & da ficha do aluno \\
\hline 20 & Caroline: & é um elemento pra cada aluno \\
\hline 21 & Karen: & não [.] cada aluno tem três elementos [.] essa prova dura vinte minutos \\
\hline 22 & & três elementos e cinco minutos de perguntas sobre a vida dele e sobre \\
\hline 23 & & o questionário que ele responde [.] então, vamos lá vamos pegar um \\
\hline 24 & & aluno [.] sei lá [.] a Valesca [..] a Valesca \\
\hline 25 & Caroline: & a Valesca uhum \\
\hline 26 & Karen: & ela é $[. .$.$] (com a pausa olba para Caroline)$ \\
\hline 27 & Caroline: & a Valesca é fofa (Karen ri) \\
\hline 28 & Karen: & não [.] isso não importa (Caroline e Karen riem alto pelo comentário \\
\hline 29 & & de (aroline) \\
\hline 30 & Karen: & independe se ela é fofa ou não dá igual (Caroline gargalba alto e agudo) \\
\hline 31 & Karen: & o que que a Valesca faz [.] eu não sei [..] \\
\hline 32 & Caroline: & eu não sei exatamente \\
\hline 33 & Karen: & nem eu \\
\hline 34 & Caroline: & não sei também \\
\hline 35 & Karen: & ai meu deus, tô ferrado (baixo) espera só um pouquinho Caroline então \\
\hline 36 & & [..] a Valesca depois eu vejo isso o (Sussurrando. Karen está folbeando \\
\hline 37 & & algumas páginas, e fica séria olbando as páginas.) depois a gente vê \\
\hline 38 & & isso [.] se não a Flávia [.] tá [.] vamos fingir que a Valesca é médica \\
\hline 39 & & vamos pegar elementos que têm a ver com a profissão dela que é mais \\
\hline 40 & & fácil ela desenvolver \\
\hline 41 & Caroline: & uhum (está atenta a Karen) \\
\hline 42 & Karen: & vou pegar um elemento que \\
\hline 43 & Caroline: & mas você não conhece [..] \\
\hline 44 & Karen: & não [.] você conhece os alunos porque nós aplicamos o Celpe \\
\hline 45 & Caroline: & sim mas eu digo pra você [.] ah tá \\
\hline 46 & Karen: & então [.] eu conheço a Valesca \\
\hline 47 & Caroline: & mas se tiver algum aluno que você não conheça \\
\hline 48 & Karen: & eu pergunto pros outros mas eles respondem a um questionário \\
\hline 49 & Caroline: & ah tá \\
\hline 50 & Karen: & e aí com base no questionário dele eu vou ver ó (inaudível) nós fazemos \\
\hline 51 & & aqui (Aponta para o caderno de questões) um mais ou menos fácil \\
\hline 52 & & médio [.] sei lá a prova de chá verde Valesca é médica então vou pegar \\
\hline
\end{tabular}




\begin{tabular}{|c|c|c|}
\hline 53 & & esse daqui do chá verde \\
\hline 54 & Caroline: & o que que é esse aqui \\
\hline 55 & Karen: & (inaudivel) \\
\hline 56 & Caroline: & $\begin{array}{l}\text { (com a lista de elementos de uma edição do exame, na qual bá sinais a lápis de menos e mais } \\
\text { ao lado de }\end{array}$ \\
\hline 57 & & cada título de elemento) menos mais \\
\hline 58 & & {$[.$.$] o que que é isso$} \\
\hline 59 & Karen: & mais ou menos mais fácil menos fácil \\
\hline 60 & Caroline: & ahnnm \\
\hline 61 & Karen: & (inaudível) \\
\hline 62 & & (Flávia entra na sala falando alto, mostrando seus fichários recheados \\
\hline 63 & & de elementos provocadores. Flávia começa a mostrar como estão \\
\hline 64 & & divididos. Karen e Caroline, que estão agachadas com muitos \\
\hline 65 & & elementos na mão, olbando para Flávia, que segue explicando a \\
\hline 66 & & divisão dos fichários por edição do exame. Flávia enfatiza que é uma \\
\hline 67 & & relíquia e que nem no instituto tem tudo o que ela tem. \\
\hline 68 & & Karen pede que Flávia espere um pouco e que acompanbe a explicação \\
\hline 69 & & que está dando a Caroline para ver se está certa. Flávia acompanba.) \\
\hline 70 & Karen: & (olhando para Caroline) e aí [.] conforme [.] vou pegar lá um elemento \\
\hline 71 & & pra Valesca (olbando para Flávia) essa é a primeira vez que eu tô \\
\hline 72 & & explicando certinho (olbando novamente para Caroline) a primeira \\
\hline 73 & & pergunta (aponta para uma ficha) é obrigatória [.] os primeiros \\
\hline 74 & & cinco minutos ela fala sobre a vida dela nada pessoal assim ah foi \\
\hline 75 & & pro Brasil por que tá fazendo o Celpe cinco minutos [.] acabou \\
\hline 76 & & aí você passa pra primeira pergunta [.] essa é obrigatória depois você \\
\hline 77 & & tem essas aqui pra tu seguir nos próximos cinco minutos \\
\hline 78 & Caroline: & uhm \\
\hline 79 & Karen: & tá certo né (olbando para Flávia) \\
\hline 80 & Flávia: & se qualquer ideia das perguntas Caroline [..] umm [...] o aluno tem que \\
\hline 81 & & falar e ele tem que falar durante cinco minutos. \\
\hline 82 & Karen: & vinte \\
\hline 83 & Flávia: & não tem que falar cinco minutos com cada elemento desses [.] no total \\
\hline 84 & & a prova é vinte minutos \\
\hline 85 & & (Flávia passa a explicar o que Karen já havia explicado, dando alguns \\
\hline
\end{tabular}




\begin{tabular}{|c|l|l|}
\hline 86 & & exemplos, de modo muito semelhante ao que Karen já vinha fazendo. \\
\hline 87 & & Flávia está séria. Retoma os elementos, a ficha do aluno. Flávia fala \\
\hline 88 & de como se caracteriza a escolba dos elementos, um mais fácil, mais \\
\hline 89 & difícil, mais fácil, de acordo com a relação do tema do elemento com a \\
\hline 90 & vida do aluno) \\
\hline & (Diário 5, p. 13,14 e 15-Observação participante 24/02/12 - reunião pedagógica) \\
\hline
\end{tabular}

Com a saída de Flávia da sala, Karen passa a se responsabilizar pelo gerenciamento do trabalho. Karen, ao ofertar ajuda, elabora perguntas e as responde (linhas 2, 5, 6, 7 e 8), Caroline se engaja, o que se percebe por meio dos recibos (linhas, 3, 4, 10 e 17) que dá a Karen de que está acompanhando as explicações. $\mathrm{O}$ treinamento dos professores aplicadores do exame é recriado e reinterpretado por Karen ao desenvolver sua explicação a Caroline. Em sua explicação, Karen descreve o processo de aplicação e treinamento passo a passo (leitura das fichas dos candidatos, leitura dos elementos provocadores, seleção de elementos provocadores para candidatos). Karen procura dar concretude a sua explicação por meio da escolha de um exemplo prático: uma aluna, possível candidata ao exame, para que o processo de escolha de um elemento fique mais claro para Caroline (linhas 21 a 24).

Os modos de participação são definidos entre as duas participantes, sendo que Karen gerencia uma explicação e Caroline sustenta isso, e a atividade que se interpõe (as explicações de Karen sobre como funciona o Celpe-Bras) é compreendida pelas participantes como fundamental para o bom cumprimento da tarefa de selecionar os elementos para a prova oral. Karen reconhece que, para Caroline, é difícil realizar o trabalho com qualidade sem entender precedentes importantes, como a aplicação do exame. $\mathrm{O}$ espaço da reunião pedagógica em pequenos grupos propicia viver a experiência dos professores como formadores e formandos. Karen assume uma postura de formadora e Caroline sustenta tal postura assumindo a de formanda. Com a chegada de Flávia de volta à sala, tais papéis se reatualizam, e Karen passa a ser uma formadora em formação, ao solicitar a Flávia (linhas 70 a 77) que observe suas explicações para avaliar se estão corretas.

Interpretar e narrar a experiência vivida com um dado aspecto que compõe a realidade desse instituto (um posto aplicador do Celpe-Bras) é componente essencial para a formação dos professores com base na prática. A estratégia de Sônia ao escolher os integrantes dos grupos surte efeito pelo modo como os mais experientes gerenciam o trabalho com colegas menos experientes, o que se observa 
pelo modo como os participantes se engajam em atividades colaborativas para dar ao menos experiente acesso aos modos de funcionamento das práticas vigentes.

\section{CONSIDERAÇÕES FINAIS}

A participação em eventos como os aqui apresentados e discutidos é estruturada em torno do esforço em responder às dúvidas do outro, oferecendo modos de explicar um tópico específico, integrante dos conteúdos curriculares que os participantes devem ensinar em suas aulas, ou na introdução dos menos experientes às práticas do local em questão. Há uma base que possibilita o desenho das ações desempenhadas em um evento de formação: a cultura de que se compartilha o que se sabe. A colaboração pode ocorrer por meio do oferecimento de respostas às dúvidas ou da oferta de uma explicação com base na relevância desta para a prática de outro participante. A relevância da ajuda provida pode ser vista no modo como a participação segue, ou em sinalizações verbais de que se entende o propósito de uma oferta de ajuda. Nóvoa (1995) enfatiza que as experiências dos professores compõem a pedagogia essencial da formação e, conforme o que autores como Pérez Gómez (1995) e Perrenoud (2002) propõem, seria desejável que a formação de professores priorizasse a resolução de problemas oriundos da prática, e é isso, juntamente ao compartilhamento de experiências, que pode ser apreciado nos dados. Além disso, em eventos de formação, os problemas não são necessariamente expostos, discutidos e resolvidos em um único evento, mas eles incorporam ações que podem promover a resolução de problemas em uma ou diversas etapas. $\mathrm{O}$ evento em que as três participantes trabalham com os elementos provocadores da prova oral do exame Celpe-Bras tem início quando Sônia designa as atividades a serem cumpridas naquela reunião decidindo previamente que o encontro entre Flávia, Karen e Caroline seria produtivo como momento de aprendizagem para Caroline.

Algumas questões devem ser levantadas quanto à proposição de que são os eventos de formação o lócus onde a formação se desenvolve. Primeiramente, os eventos de formação descritos aqui, representativos de uma coleção de 30 eventos selecionados de uma coleção mais ampla, sinalizam que há formação na medida em que os participantes demonstram uns para os outros quais conhecimentos são relevantes para serem aprendidos. Por um lado, há eventos em que uma necessidade de ordem prática e um pedido de ajuda desencadeiam explicações de conhecimentos de ordem teórica, como no dado em que Lúcia e Alberto explanam os usos do 
infinitivo pessoal a Priscila. Por outro lado, há momentos em que conhecimentos de ordem teórica podem ser mobilizados sem uma necessidade premente de uso em sala de aula ou sem um pedido explícito de ajuda, como no caso do dado em que Karen e Flávia ensinam a Caroline como o exame Celpe-Bras funciona. Além disso, vemos que os participantes mais experientes podem se responsabilizar ou serem responsabilizados pela formação de colegas menos experientes e que definem, na interação, as estratégias de compartilhamento de tais experiências.

O fato de todos os eventos acontecerem no local de trabalho dos participantes e pela demanda sempre presente de uso imediato do conhecimento, uma possível ênfase no tratamento técnico de algum problema logo passa a ser contextualizada e adaptada às necessidades prementes do aqui e agora. Nesse sentido, vale ressaltar, conforme aponta Nóvoa (1995), que a troca de experiências e saberes consolida espaços de formação mútua por meio de um processo constante de reflexividade sobre as práticas. Nos dados aqui analisados, foi possível observar que essas práticas dizem respeito a esse local de trabalho específico, o que implica uma construção da identidade pessoal de ser professor que reflete e refrata o que é valorizado nesse instituto.

Em segundo lugar, seriam necessários mais estudos para confirmar que são as perguntas o que move os eventos de formação. Pelo que podemos ver nos dados até aqui, perguntas são fundamentais, e configuram pedidos de ajuda a participantes legitimados como os mais experientes. No entanto, trabalhos microanalíticos com o foco em aprendizagem poderiam contribuir para uma conceituação mais robusta de eventos de formação, no sentido de incluir na caracterização do evento, além do momento propício para aprender, a evidência de que houve aprendizado.

Procuramos argumentar que eventos de formação são eventos em que os participantes têm o ensino como foco de suas ações. Os eventos analisados sugerem uma visão dos participantes sobre ser professor nesse instituto: o professor é um profissional que conhece as regras gramaticais e o Celpe-Bras, está preparado para explicá-los, e para lançar mão de estratégias de ensino ${ }^{10}$. Os eventos de formação podem ser vistos, assim, como momentos propícios para aprender a ser professor nesse local de trabalho. Estudiosos como Schön (2000) e Nóvoa (1995), fundamentais para a conceituação de formação de professores que adotamos neste trabalho, não diferenciam aprendizagem de formação, e usam os termos em algumas

10 Nos dados analisados em COSTA (2013), o escopo de ações que os participantes desempenham e de conhecimentos que exibem e compartilham é mais amplo que o apresentado aqui. Estratégias para aplicação de provas orais, elaboração e uso de materiais didáticos em sala de aula, aprendizagens sobre a cultura do local onde a pesquisa foi realizada são outras manifestações que caracterizam os eventos de formação. 
situações como sinônimos. Nos dados discutidos, a relação entre ensinar e aprender a ser professor parece ser bastante estreita, pois, como vimos, as explicações sobre regras e sobre como explicá-las, a apresentação de modelos de como fazer ensinar, os relatos do que foi feito são motivados por problemas comuns e que demandam o uso imediato desse conhecimento para seguir adiante no que os participantes estão fazendo e no futuro muito próximo e concreto das próximas aulas.

\section{REFERÊNCIAS BIBLIOGRÁFICAS}

BOURDIEU, P. (1977). Outline of a theory of practice. Cambridge: Cambridge University Press.

COSTA, E.V. (2013). Práticas de formação de professores de Português Lingua Adicional em um instituto cultural brasileiro no exterior. Dissertação de Mestrado em Letras. Universidade Federal do Rio Grande do Sul, Porto Alegre.

GARCEZ, P.M.; SALIMEN, P.G. (2011). Pedir e oferecer ajuda para "fazer aprender" em atividades pedagógicas de encenação na fala-em-interação de sala de aula de inglês como língua adicional. In: Barcelos A.M. (Org.), Linguística Aplicada: reflexões sobre ensino e aprendizagem de língua materna e língua estrangeira. Campinas: Pontes. p. 97-117

HAMMERSLEY, M.; ATKINSON, P. (1995). Etnografía: Métodos de Investigación. Barcelona: Paidós.

JUDD, E. L.; TAN, L.; WALBERG, H. J. (2001). Teaching additional languages. Switzerland, IBE Publications Unit. Disponível em http://www.ibe.unesco.org/fileadmin/user_upload/archive/ Publications/educationalpracticesseriespdf/prac06e.pdf

Acesso em 4 de agosto de 2016.

LIMA, E. E. O. F et al. (1991). Avenida Brasil 2: curso básico de português para estrangeiros. São Paulo: EPU,

NÓVOA, A. Formação de professores e profissão docente. (1995). In: Nóvoa, A. (Org.). Os professores e a sua formaçãa. 2 ed. Lisboa: Dom Quixote,.

NÓVOA, A. (2007). O Regresso dos Professores. Conferência Desenvolvimento profissional de professores para a qualidade e para a equidade da Aprendizagem ao longo da Vida. Lisboa: Presidência Portuguesa do Conselho da União Europeia.

PÉREZ GÓMEZ, A. (1995). O pensamento prático do professor: a formação do professor como profissional reflexivo. In: Nóvoa, A. (Org.). Os professores e a sua formação. 2 ed. Lisboa: Dom Quixote.

PERRENOUD, P. (2002). A Prática Reflexiva no Ofício de Professor: Profissionalização e Razão Pedagógica. Porto Alegre: ARTMED.

RIBEIRO, B. T.; GARCEZ, P. M. (1998). Sociolinguística Interacional: antropologia, linguística e sociologia em análise do discurso. Porto Alegre: Loyola.

SCHLATTER, M. GARCEZ, P. (2009). Referenciais Curriculares para o Ensino de Língua Espanbola e de Língua Inglesa. Rio Grande do Sul: Secretaria de Educação do Estado,.

SCHÖN, D. (2000). Educando o Profissional Reflexivo: um novo design para o ensino e aprendizagem. Porto Alegre: ARTMED.

Recebido: 04/08/216

Aceito: 13/02/2017 